\title{
Ethinyl Estradiol Decreases Acidification of Rat Liver Endocytic Vesicles
}

\author{
REBECCA W. VAN DYKe AND KaREN V. ROOT \\ Division of Gastroenterology, Department of Medicine, University of Michigan School of Medicine, \\ Ann Arbor, Michigan 48109-0682
}

Treatment with ethinyl estradiol is known to impair bile formation, bile acid transport and $\mathrm{Na}, \mathrm{K}$-ATPase activity, to alter receptor-mediated endocytosis and transcytosis of IgA and asialoorosomucoid and to affect membrane lipid composition and fluidity. Because appropriate sorting and trafficking of asialoorosomucoid requires adequate acidification of endocytic vesicles by a lipid-sensitive electrogenic proton pump, we examined the effects of 5 days of treatment with ethinyl estradiol ( $5 \mathrm{mg} / \mathrm{kg}$ body wt, subcutaneously) on acidification of early endosomes prepared from male rat livers. Littermate control animals received equal volumes of the solvent propylene glycol. Pretreatment with ethinyl estradiol reduced ATP-dependent initial rates of endosome acidification by $11 \%$ to $25 \%$ when measured in potassium medium containing 0 to 140 $\mathrm{mmol} / \mathrm{L}$ chloride; these differences were significant at four of six chloride concentrations tested. The proton pumps of ethinyl estradiol and propylene glycol endosomes exhibited similar Michaelis-Menten constants for MgATP (Michaelis-Menten constant of 63 and 66 $\mu \mathrm{mol} / \mathrm{L}$ in the absence of chloride and 101 and 126 $\mu \mathrm{mol} / \mathrm{L}$ in the presence of chloride, respectively). Acidification of ethinyl estradiol and propylene glycol endosomes changed in the same manner when various cations or anions were substituted for potassium gluconate, although the effects of ethinyl estradiol were less marked in the absence of $\mathrm{K}^{+}$. Kinetics of inhibition for ethinyl estradiol and propylene glycol endosomes were similar for the proton pump inhibitors $N$-ethylmaleimide $(50 \%$ inhibitory concentrations of 13.5 and $18.1 \mu \mathrm{mol} / \mathrm{L})$, dicyclohexylcarbodiimide $(50 \%$ inhibitory concentrations of 206 and $216 \mu \mathrm{mol} / \mathrm{L}$ ) and bafilomycin A $(50 \%$ inhibitory concentrations of 11 and $6 \mathrm{nmol} / \mathrm{L})$. Although initial rates of acidification were slower in ethinyl estradiol endosomes, ATP-dependent

Received September 10, 1992; accepted April 3, 1993.

This study was carried out with the technical assistance of Loretha L. Ervin.

This work was supported by National Institutes of Health grant RO1 DK-38333 to R.W. Van Dyke.

A portion of this work was presented at the meeting of the International Association for the Study of the Liver in Brighton, U.K., June 5, 1992, and published in abstract form (HEPATOLOCY 1992;16:605).

Address reprint requests to: Rebecca W. Van Dyke, 6520 MSRB-I, University of Michigan Medical Center. Ann Arbor, MI 48109-0682.

Copyright 1993 by the American Association for the Study of Liver Diseases.

$0270-9139 / 93 \$ 1.00+.10 \quad \mathbf{3 1} / \mathbf{1} / \mathbf{4 8 1 1 6}$ steady-state vesicle interior $\mathrm{pH}$ was the same as that of propylene glycol endosomes over a range of chloride concentrations; this appeared to be due mainly to a trend toward decreased proton leak rates in ethinyl estradiol endosomes. Overall, ethinyl estradiol treatment modestly decreased initial rates of acidification and vesicle proton leakage, perhaps because of changes in endosome lipid composition; differences in the number, density or activation state of proton pumps; or differences in endosome geometry. Because the decrease in acidification rates was small, the effects of estrogen on the efficiency of uncoupling of endocytosed ligands such as asialoorosomucoid from their receptors in early endosomes; thus the rates of sorting and distribution of ligands remain unclear. (HePATOlogy 1993;18:604-613.)

Endocytic vesicles and other intracellular organelles contain an electrogenic proton pump or vacuolar $\mathrm{H}^{+}$. ATPase (1-3) that appears to function in parallel with a chloride conductance (3-7) to maximally acidify the interiors of these vesicles. This interior acidic $\mathrm{pH}\left(\mathrm{pH}_{\mathrm{i}}\right)$ is essential for normal receptor-mediated endocytosis and degradation of macromolecules $(2,3,8-11)$ and processing, sorting and secretion of some proteins from the Golgi apparatus (10). Changes in vesicle acidification may alter these cell functions (8-10), but little is known about mechanisms for regulating vesicle acidification in vivo. The liver is very active in the receptor-mediated endocytosis and degradation of lipoproteins and asialoglycoproteins and exhibits an active transcytotic pathway from sinusoidal blood to bile $(11,12)$. Therefore it is a good model for studying the relationship between changes in vesicle acidification and the sorting and degradation of macromolecules.

Ethinyl estradiol (EE) treatment is known to inhibit hepatic bile formation (13-19) and bile acid transport (17-19) and to affect ion pumps such as Na,K-ATPase (13-19) and $\mathrm{Ca}^{+2}$-ATPase (20). Previous investigators have shown that in rat liver this agent alters sorting of asialoglycoprotein asialoorosomucoid (ASOR) subjected to endocytosis and reduces transcytotic movement of IgA from blood to bile (12). Because correct sorting, delivery and degradation of asialoglycoproteins requires adequate vesicle acidification, we undertook these studies to determine whether EE altered acidification of 
the early rat liver endosomes involved in sorting and delivery of protein ligands to lysosomes.

\section{MATERIALS AND METHODS}

Materials. All chemicals except ATP (Boehringer Mannheim, Indianapolis, IN) and fluorescein antibody (Molecular Probes, Inc., Eugene, OR) were purchased from Sigma Chemical Co. (St. Louis, MO). Bafilomycin $\mathrm{A}_{1}$ was the kind gift of Dr. Karlheinz Altendorf (University of Osnabruck, Osnabruck, Germany); it was prepared as a stock solution in DMSO. Carbonyl cyanide m-chlorophenylhydrazone (CCCP), dicyclohexylcarbodiimide (DCCD) and monensin were prepared as stock solutions in ethanol. N-ethylmaleimide (NEM) was prepared daily as a stock solution in distilled water. Before use 70,000 Da FITC-conjugated dextran (FITC-dextran) was purified by dialysis for 4 or 5 days against $20 \mathrm{mmol} / \mathrm{L}$ phosphate buffer ( $\mathrm{pH} 7.0$ ), lyopholized and stored at $-20^{\circ} \mathrm{C}$.

Animal Preparation. Rats were housed and treated in accordance with a protocol approved by the University of Michigan Committee on the Care and Use of Animals in accordance with the guidelines outlined by the Institute of Laboratory Animal Resources and the National Institutes of Health. For these studies, male Sprague-Dawley rats were treated with EE ( $5 \mathrm{mg} / \mathrm{kg}$ body wt, subcutaneously) for 5 days. Control animals were littermates given identical volumes of the solvent propylene glycol (PG). Animals were purchased, housed and treated as pairs (one animal given $\mathrm{EE}$ and the other PG), and endosomes were prepared and assayed simultaneously each day from an EE-treated animal and its PGtreated littermate control.

Isolated Endosomes. Early (10-min) endosomes were prepared as a microsomal pellet from male Sprague-Dawley rat liver $10 \mathrm{~min}$ after intravenous injection of $50 \mathrm{mg} 70,000 \mathrm{Da}$ FITC-dextran dissolved in $1 \mathrm{ml}$ normal saline solution. Livers were rapidly chilled by perfusion with ice-cold sucrose buffer (250 $\mathrm{mmol} / \mathrm{L}$ sucrose and $3 \mathrm{mmol} / \mathrm{L}$ imidazole, $\mathrm{pH} 7.4$ ), chopped into small pieces ( 1 to $2 \mathrm{~mm}$ ) with scalpels and homogenized in 5 vol of ice-cold sucrose buffer by six passes of a loose-fitting Dounce homogenizer and one pass of a tightfitting Dounce homogenizer. Homogenates were centrifuged at $1,000 g_{\text {average }}$ for $10 \mathrm{~min}$ to remove nuclei and unbroken cells. Supernatants were removed and centrifuged at 10,000 $g_{\text {average }}$ for $20 \mathrm{~min}$. Supernatants were removed, and a microsomal pellet that contained low-density fluorescent endosomes was prepared by centrifugation at $100,000 g_{\text {average }}$ for 60 $\mathrm{min}$. Pellets were resuspended in a small volume of ice-cold potassium gluconate buffer $(140 \mathrm{mmol} / \mathrm{L}$ potassium gluconate and $30 \mathrm{mmol} / \mathrm{L} b i s \mid 2$-hydroxyethyl]imino-tris[hydroxymethyl] methane [Bis-Tris], $\mathrm{pH}$ 7.0, with piperazine- $\mathrm{N}-\mathrm{N}^{\prime}$-bis[2-ethane sulfonic acid] [PIPES]) with a small, loose Dounce homogenizer. For some studies, endosomes were resuspended in a similar buffer in which N-methyl-D-glucamine (NMDG) replaced $\mathrm{K}^{+}$. All endosomes were used within $6 \mathrm{hr}$ of preparation, and EE and PG endosomes were assayed alternately to eliminate time-dependent variations in ion transport.

Vesicle Acidification. Vesicle $\mathrm{pH}\left(\mathrm{pH}_{\mathrm{i}}\right)$ was assessed on the basis of the ratio of fluorescein fluorescence at two excitation wavelengths (excitation $=493 \mathrm{~nm}$ and $450 \mathrm{~nm}$; emission $=530 \mathrm{~nm})$ and a standard curve relating $\mathrm{pH}_{\mathrm{i}}$ to fluorescence ratio as measured with a computer-controlled dualexcitation wavelength spectrofluorometer (SPEX Industries, Edison, NH) as described previously (21-24). Experiments were performed at $22^{\circ} \mathrm{C}$. For each assay, 500 to $700 \mu \mathrm{g}$ endosomes were added to acrylic cuvettes containing $2 \mathrm{ml}$ isotonic buffer (a mixture of $140 \mathrm{mmol} / \mathrm{L} \mathrm{KCl}$ and $140 \mathrm{mmol} / \mathrm{L}$ potassium gluconate yielding the desired chloride concentration or isotonic amounts of other salts with $30 \mathrm{mmol} / \mathrm{L}$ Bis-Tris [pH 7.01) 5 min before use with other additions as indicated in figure legends and tables. For all studies, cuvettes also contained sufficient fluorescein antibody to quench fluorescence of extravesicular fluorescein. To initiate acidification, we added $5 \mathrm{mmol} / \mathrm{L}$ MgATP. After we achieved steady state, we added proton ionophores $(8 \mu \mathrm{l}$ of an ethanol stock of $5 \mathrm{mmol} / \mathrm{L}$ monensin and $2 \mathrm{mmol} / \mathrm{L}$ CCCP) to eliminate all $\mathrm{pH}$ gradients, and a standard curve relating $\mathrm{pH}$ to fluorescence ratio was determined. Over the range of $\mathrm{pH}$ employed in these studies, the ratio of fluorescein fluorescence at $493 \mathrm{~nm} / 450 \mathrm{~nm}$ was linearly related to $\mathrm{pH}$. Each plot of fluorescence ratio vs. time was converted to a plot of $\mathrm{pH}_{\mathrm{i}}$ vs. time with the standard curve. Initial rates of ATP-dependent acidification were calculated from the slope of a line, fit by eye, of vesicle $\mathrm{pH}_{\mathrm{i}}$ vs. time, and steady-state $\mathrm{pH}_{\mathrm{i}}$ was taken as the lowest stable value obtained (Fig. 1). This method for measuring acidification rate is independent of the number of endocytic vesicles present in the assay cuvette and the concentration of FITC-dextran in each endocytic vesicle (21-24; Van Dyke RW, Unpublished observations, 1990-1992). Indeed, in preliminary studies using these 10-minute endosomes, we confirmed that initial rates of acidification were independent of the amount of protein used in the assay (data not shown).

Plots of initial rates of acidification vs. medium concentration of MgATP or chloride were fitted, by non-linear curve-fitting (Kaleida Graph 2.1; Synergy Software, Reading, PA), on a Macintosh IIcx personal computer (Apple Computers), to functions of the form $y=a x /(b+x)+c$, and estimates for the constants were obtained. This function was selected because it best fitted the data and represents a form of a Michaelis-Menten function.

For statistical comparison of the kinetic parameters of $50 \%$ of effective dose $\left(\mathrm{ED}_{50}\right)$ and maximum velocity $\left(\mathrm{V}_{\max }\right)$ for the acidification rate vs. chloride concentration curves, data from five paired preparations of $\mathrm{EE}$ and $\mathrm{PG}$ endosomes in which a range of chloride concentrations were tested were each fitted to this function. Estimates of $E D_{50}$ and $V_{\max }$ obtained from these five separate preparations were then averaged, compared with paired Student's $t$ tests and used to generate the overall curves shown in Figure 2.

Proton Leak Rates. Proton leak rates were measured as the initial linear rate of realkalinization of vesicles after the proton pump was stopped. Endosomes were allowed to acidify to steady state by addition of $3 \mathrm{mmol} / \mathrm{L} \mathrm{MgATP}$. Then ATP was rapidly consumed by addition of $15 \mathrm{mmol} / \mathrm{L}$ glucose and 15 to 25 units of type F-300 yeast hexokinase, and the initial linear rate of realkalinization was assessed as change in $\mathrm{pH}$ per minute $(\Delta \mathrm{pH} / \mathrm{min})$. Preliminary studies showed that these amounts of glucose and hexokinase gave maximal rates of alkalinization. Small volumes $(5 \mu l)$ of ethanol or valinomycin (1 $\mathrm{mmol} / \mathrm{L}$ ) dissolved in ethanol were added concomitantly with glucose and hexokinase.

Proton Fluxes. Influx and efflux $\left(J_{H_{+}}\right)$of protons in vesicles loaded with FITC-dextran were calculated as the product of measurements of vesicle buffering capacity $(B)$ (millimoles per $\mathrm{pH})$ and the initial rates of ATP-dependent acidification or realkalinization after the proton pump was stopped: $\mathrm{J}_{\mathrm{H}+}=$ B $\cdot \Delta \mathrm{pH} / \mathrm{min}$.

Buffering capacity was measured with a modification of an ammonium-pulse technique $(22,23)$. In these studies, $\mathrm{B}$ was measured at two values of $\mathrm{pH}_{\mathrm{i}}$. We have previously shown that buffering capacity in endocytic vesicles increases with $\mathrm{pH}_{\mathrm{i}}(22$, 23). For calculation of pump-mediated proton influx rates, we used linear-regression analysis to extrapolate $\mathrm{B}$ for $\mathrm{pH}_{\mathrm{i}}$ values 


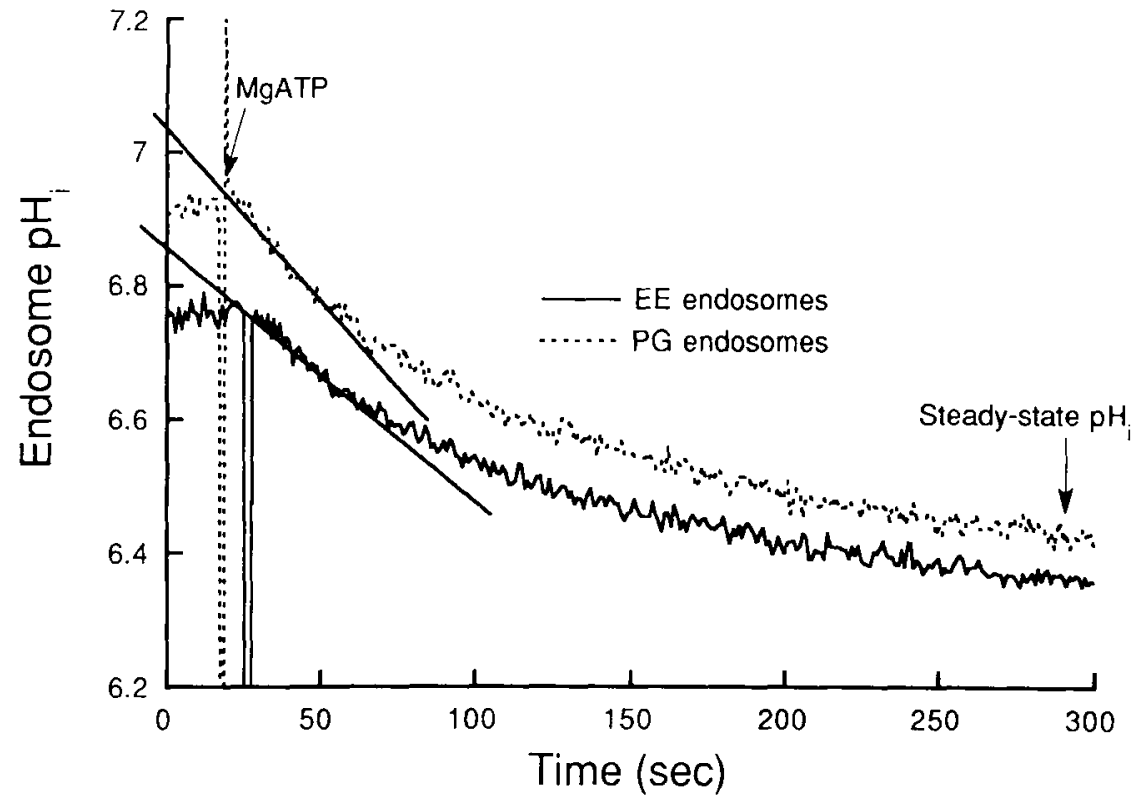

FIG. 1. Representative endosome acidification assays. FITC-dextran-loaded endosomes were prepared from EE- and PG-treated rats as described in Materials and Methods and assayed in $140 \mathrm{mmol} / \mathrm{L}$ potassium gluconate buffer. Endosomal $\mathrm{pH}_{\mathrm{i}}$ was assessed from the ratio of fluorescein fluorescence at two excitation wavelengths and a standard curve. Rates of acidification were calculated as the slopes of tangents (-) drawn to the initial portion of the acidification curve after addition of MgATP. Steady-state ATP-dependent $\mathrm{pH}_{\mathrm{i}}$ was taken as the value of $\mathrm{pH}_{\mathrm{i}}$ observed before addition of monensin. In this example, the initial rates of acidification were $0.224 \Delta \mathrm{pH} / \mathrm{min}(\mathrm{EE})$ and $0.295 \mathrm{pH} / \mathrm{min}$ $(P G)$. Curves were offset for clarity.

at the point at which MgATP was added. For calculation of proton permeabilities, we used the value of $B$ measured at the lowest $\mathrm{pH}_{\mathrm{i}}$ tested (5.99 for $\mathrm{EE}$ endosomes and 5.91 for $\mathrm{PG}$ endosomes).

Vesicle proton permeability $(P)$ was calculated from the proton efflux rate as

$$
\left.\mathrm{P}\left(10^{3} \cdot \min ^{-1}\right)=\mathrm{J}_{\mathrm{H}} \cdot\left(\mathrm{mmol} \cdot \min ^{-1}\right) /\left[\mathrm{H}^{+}{ }_{\mathrm{i}}\right]-\left[\mathrm{H}_{\mathrm{o}}^{+}{ }_{0}\right]\right)
$$

where $\left[\mathrm{H}^{+}{ }_{i}\right]$ and $\left[\mathrm{H}^{+}{ }_{0}\right]$ are intravesicular and extravesicular proton concentrations, respectively $(22,23,25)$.

Other Considerations. Protein concentrations were measured with the method of Lowry et al. (26).

Statistics. Experiments were repeated using two to 14 different preparations of vesicles; results were expressed as absolute values or as a percentage of results in concurrent controls. Results were expressed as the mean \pm S.E.M. $(n \geq 3)$ of results from different numbers of preparations. Where the sample size was at least three, experimental values were compared with control values with paired Student's $t$ tests. A p value less than 0.05 was considered statistically significant.

\section{RESULTS}

Endosomes prepared from rats treated with EE or PG exhibited ATP-dependent acidification (Fig. 1). Although endosomes used in this study were not purified, only vesicles formed during the 10-min exposure to FITCdextran contained internalized fluorescein and contributed to measurement of $\mathrm{pH}_{\mathrm{i}}$. Small amounts of free FITC-dextran, released from vesicles during homogenization and centrifugation, were sometimes present in assay cuvettes, but the fluorescence of this material was completely quenched by addition of fluorescein antibody (data not shown; 22, 23) before addition of MgATP. Incubation of endosomes with MgATP and other agents at $22^{\circ} \mathrm{C}$ did not result in release of additional FITCdextran over the course of these studies (data not shown).

In five paired preparations of endosomes, EE treatment (Fig. 2) consistently decreased the initial rate of MgATP-dependent acidification by $11 \%$ to $25 \%$ compared with $\mathrm{PG}$ treatment $(25 \%, 17.5 \%, 16.7 \%, 14.5 \%$, $10.7 \%$ and $11 \%$ in $0,2,5,10,25,140 \mathrm{mmol} / \mathrm{L} \mathrm{Cl}^{-}$, respectively); these differences were statistically significant for assays in $0(p<0.005), 2$ ( $p<0.05), 25$ $(\mathrm{p}<0.005)$ and $140(\mathrm{p}<0.05) \mathrm{mmol} / \mathrm{L}$ chloride. As noted by us in other intracellular acidified vesicles, endosome acidification was increased by increases in medium chloride concentration; this effect was probably related to neutralization of the positive charge of pumped protons by the permeable anion chloride. When the data were fit to a Michaelis-Menten-type function, estimates for the $\mathrm{ED}_{50}$ of chloride were similar for $\mathrm{EE}$ $(3.3 \pm 0.3 \mathrm{mmol} / \mathrm{L})$ and $\mathrm{PG}(3.3 \pm 1.3 \mathrm{mmol} / \mathrm{L})$ ( $\mathrm{p}=\mathrm{NS}$ ) endosomes, whereas $\mathrm{V}_{\max }$ was decreased by $11.2 \%$ in $\mathrm{EE}$ endosomes $(0.924 \pm 0.053 \Delta \mathrm{pH} / \mathrm{min}$ vs. $1.033 \pm 0.054 \Delta \mathrm{pH} / \mathrm{min}) \quad(\mathrm{p} \leq 0.05)$. These findings suggest that $\mathrm{EE}$ endosomes have fewer proton pumps per vesicle or the same density of proton pumps, which turn over more slowly than proton pumps in $P G$ endosomes.

Other explanations for the differences in acidification rates may include differences in vesicle buffering ca- 


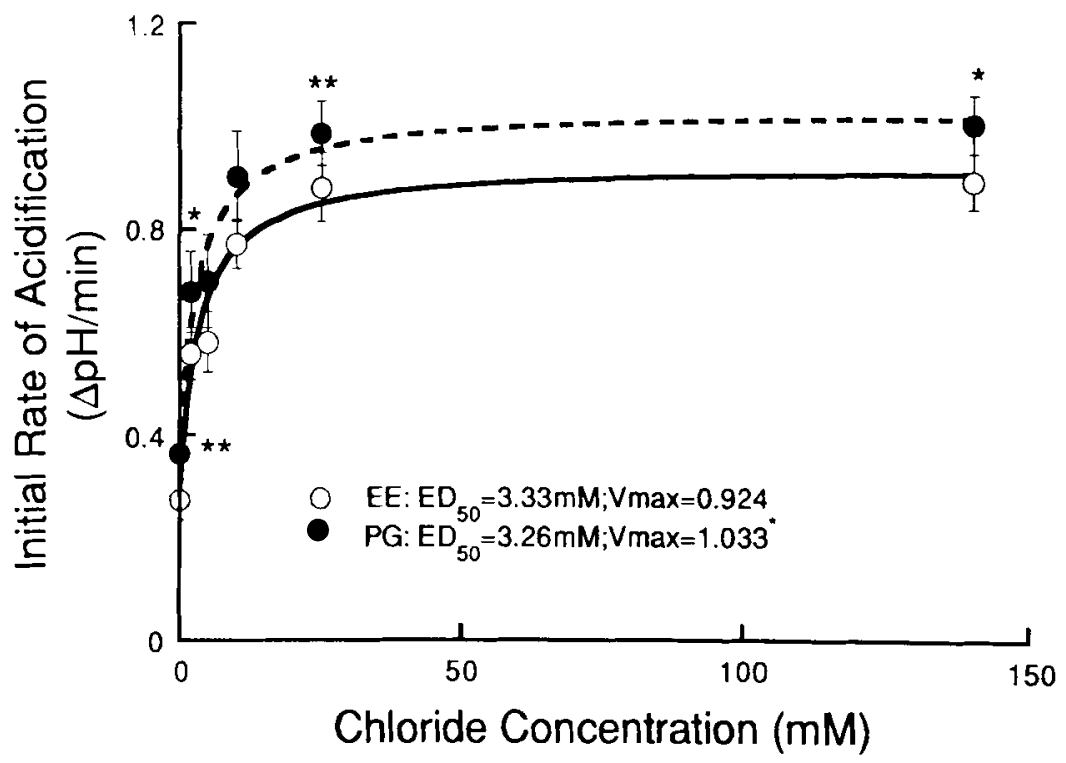

FIG. 2. Initial rates of ATP-dependent acidification of endosomes prepared from rats treated with EE $(0)$ or PG $(\bullet)$ plotted against medium chloride concentration. Vesicles were suspended in medium containing $140 \mathrm{mmol} / \mathrm{L} \mathrm{K} \mathrm{K}^{+}$with a mixture of gluconate and chloride to give the indicated $\left[\mathrm{Cl}^{-}\right]$and $30 \mathrm{mmol} / \mathrm{L}$ Bis-Tris $(\mathrm{pH} \mathrm{7.0)}$. Symbols represent mean \pm S.E.M. for results from five different paired preparations of EE and $\mathrm{PG}$ endosomes. ${ }^{*} \mathrm{p}<0.05$ compared with $\mathrm{PG} ;{ }^{* *} \mathrm{p}<0.005$ compared with $\mathrm{PG}, \mathrm{ED}_{50}$ and $\mathrm{V}_{\max }$ values were estimated from the best-fit function of the form $y=a x /(b+x)+c$ as described in Materials and Methods for each of the five different paired preparations of endosomes, and mean values for $\mathrm{ED}_{50}$ and $\mathrm{V}_{\max }$ were calculated. The curve illustrated in this figure represents those averaged parameters.

pacity. We measured buffering capacity of acidified EE and $\mathrm{PG}$ endosomes with the ammonium-pulse technique in $\mathrm{KCl}$ and in potassium gluconate medium. As shown in Table 1, buffering capacity increased with more alkaline $\mathrm{pH}_{\mathrm{i}}$, as we have previously observed for purified rat liver "late" endosomes and lysosomes (22,23). EE endosomes exhibited buffering capacities similar to but slightly lower than those of PG endosomes; values shown in Table 1 were similar to values we measured previously in 10-min endosomes prepared from untreated male Sprague-Dawley rats (23). Estimated values for $\mathrm{B}$ at the $\mathrm{pH}_{\mathrm{i}}$ where initial rates of acidification were measured were similar for $\mathrm{EE}$ and $\mathrm{PG}$ endosomes in $\mathrm{KCl}(89.2 \mathrm{mmol} / \Delta \mathrm{pH}$ and $88.2 \mathrm{mmol} / \Delta \mathrm{pH}$, respectively) and in potassium gluconate $(90.2 \mathrm{mmol} / \Delta \mathrm{pH}$ and $93.1 \mathrm{mmol} / \Delta \mathrm{pH}$, respectively) media. Therefore the total ATP-dependent proton influx rates $\left(\mathrm{J}_{\mathrm{H}^{+}}\right)$in EE and PG endosomes exhibited differences analogous to those shown in Figure 2. $\mathrm{J}_{\mathrm{H}^{+}}$for $\mathrm{EE}$ endosomes was 79 $\mathrm{mmol} / \mathrm{min}(25 \mathrm{mmol} / \mathrm{L} \mathrm{KCl})$ and $25 \mathrm{mmol} / \mathrm{min}$ (potassium gluconate); for $\mathrm{PG}$ endosomes it was $87 \mathrm{mmol} / \mathrm{min}$ (25 $\mathrm{mmol} / \mathrm{L} \mathrm{KCl)}$ and $34 \mathrm{mmol} / \mathrm{min}$ (potassium gluconate).

To further explore the mechanism by which EE altered endosome acidification, we examined the kinetic response of endosome acidification to changes in the concentration of MgATP, the energy source for the proton pump. As shown in Figure 3, EE treatment did not affect the apparent affinity of the proton pump for MgATP in the presence or absence of chloride. Apparent $\mathrm{K}_{\mathrm{m}}$ values for $\mathrm{MgATP}$, estimated from the functions shown in Figure 2, were, in potassium gluconate medium, $67 \mu \mathrm{mol} / \mathrm{L}(\mathrm{EE})$ and $64 \mu \mathrm{mol} / \mathrm{L}(\mathrm{PG})$; in $\mathrm{KCl}$
TABLE 1. Buffering capacities of endosomes

\begin{tabular}{lcccc}
\hline \multicolumn{1}{c}{ Buffer ion } & $\mathbf{p H i}^{\boldsymbol{c}}$ & $\begin{array}{c}\mathbf{E E} \\
(\mathbf{m m o l} / \mathbf{p H})^{\circ}\end{array}$ & $\mathbf{p H}_{\mathbf{i}}$ & $\begin{array}{c}\mathbf{P G} \\
(\mathbf{m m o l} / \mathbf{p H})^{\circ}\end{array}$ \\
\hline $\mathrm{KCl}$ & 5.99 & $40.8 \pm 1.2$ & 5.91 & $42.8 \pm 1.4$ \\
Potassium gluconate & 6.19 & $57.7 \pm 2.2$ & 6.16 & $58.8 \pm 2.2$ \\
\hline
\end{tabular}

${ }^{a} \mathrm{pH}_{i}$ indicates intravesicular $\mathrm{pH}$ at the time $\mathrm{NH}_{4} \mathrm{Cl}$ was added to assess buffering capacity.

${ }^{b}$ Values expressed as mean \pm S.E.M of assays performed in duplicate in four separate pairs of endosome preparations.

medium they were $102 \mu \mathrm{mol} / \mathrm{L}(\mathrm{EE})$ and $126 \mu \mathrm{mol} / \mathrm{L}$ (PG). Thus EE did not appear to alter the catalytic structure of the proton pump.

The endosome proton pump is electrogenic, and rates of acidification of endocytic vesicles are determined in part by the presence of relatively permeable chargeneutralizing anions or cations that reduce pump-generated membrane potential $(\Delta \Psi)$ and increase $\Delta \mathrm{pH} / \mathrm{min}$ $(22,23,27)$. Because EE could affect permeability of counteranions or cations, we examined the response of acidification rates of $\mathrm{EE}$ and $\mathrm{PG}$ endosomes to replacement of potassium and gluconate with a variety of anions and cations (Table 2). As we have shown previously for other endocytic vesicles $(23,27)$, anion replacement substantially altered acidification rates of both EE and $P G$ endosomes in the sequence $\mathrm{Cl}^{-}$, $\mathrm{Br}^{-}>$gluconate $>\mathrm{NO}_{3}{ }^{-}, \mathrm{PO}_{4}^{-2}>\mathrm{SO}_{4}^{-2}$. The reduced acidification rates seen with the bulky anions $\mathrm{PO}_{4}^{-2}$ and $\mathrm{SO}_{4}{ }^{-2}$ and with the usually more permeable $\mathrm{NO}_{3}{ }^{-}$(27) may reflect poor permeability and modest direct inhibitory effects on the proton pump $(3,27)$. Cation substitution had little effect as long as chloride 


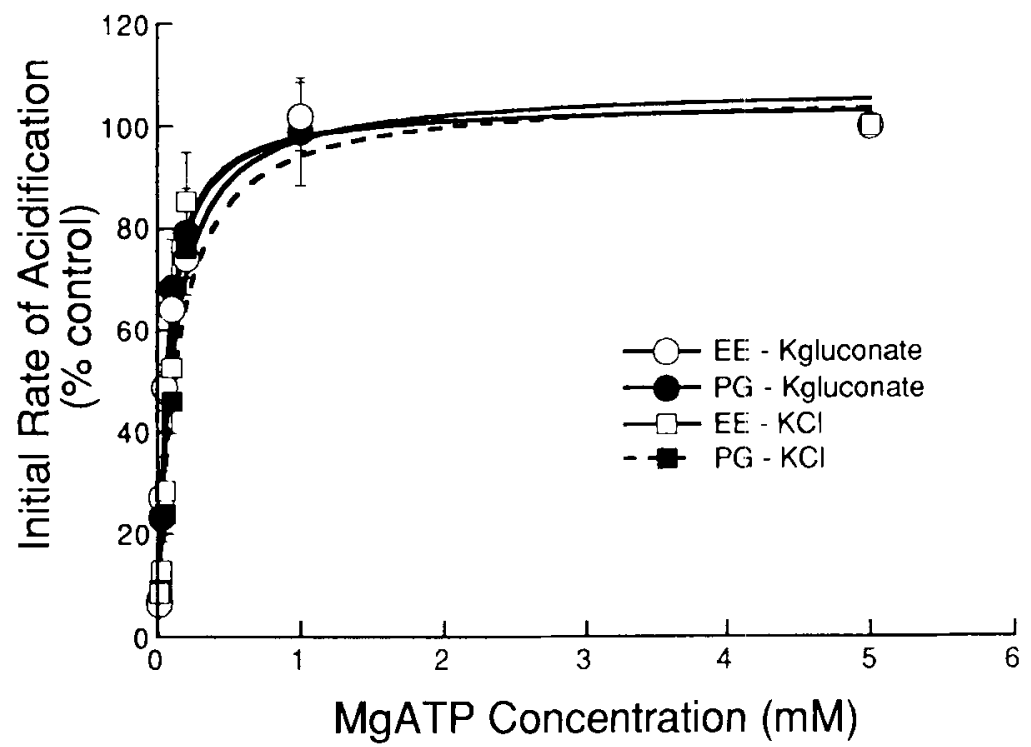

FIG. 3. Fffect of changes in MgATP concentration on initial rates of acidification of EE-treated and PG-treated endosomes. Endosomes were resuspended and assayed in buffer containing $30 \mathrm{mmol} / \mathrm{L}$ Bis-Tris $(\mathrm{pH} 7.0$ ) and $140 \mathrm{mmol} / \mathrm{L}$ potassium gluconate (circles) or $140 \mathrm{mmol} / \mathrm{L} \mathrm{KCl}$ (squares). Data expressed as percentages of values obtained in experiments performed on the same day using the same endosome preparation after addition of $5 \mathrm{mmol} / \mathrm{L} \mathrm{MgATP}$. Symbols represent the mean \pm S.E.M. ( $\mathrm{n} \geq 3$ ) of results from two or three different paired preparations of endosomes. $\mathrm{K}_{\mathrm{m}}$ values for MgATP were estimated, as described in Materials and Methods, as $67 \mu \mathrm{mol} / \mathrm{L}$ ( $\mathrm{EE}$, potassium gluconate), $64 \mu \mathrm{mol} / \mathrm{L}$ ( $\mathrm{PG}$, potassium gluconate), $102 \mu \mathrm{mol} / \mathrm{L}(\mathrm{EE}, \mathrm{KCl})$ and $126 \mu \mathrm{mol} / \mathrm{L}(\mathrm{PG}, \mathrm{KCl})$.

TABLE 2. Effect of ion substitution on initial rates of acidification

\begin{tabular}{lccc}
\hline \multicolumn{1}{c}{ Ion } & $\begin{array}{c}\text { Concentration } \\
(\mathbf{m m o l} / \mathbf{L})\end{array}$ & $\begin{array}{c}\text { EE (\% of 140 mmol/L } \\
\text { potassium gluconate) }\end{array}$ & $\begin{array}{c}\text { PG (\% of 140 mmol/L } \\
\text { potassium gluconate) }\end{array}$ \\
\hline $\mathrm{KCl}$ & 140 & 246 & 278 \\
$\mathrm{KBr}$ & 140 & 221 & 276 \\
$\mathrm{KNO}_{3}$ & 140 & 90 & 55 \\
$\mathrm{~K}_{2} \mathrm{HPO}_{4} /$ sucrose & $70 / 70$ & 70 & 94 \\
$\mathrm{~K}_{2} \mathrm{SO}_{4} /$ sucrose & $70 / 70$ & 54 & 49 \\
$\mathrm{NaCl}$ & 140 & 268 & 313 \\
$\mathrm{LiCl}$ & 140 & 439 & 404 \\
Tetramethylammonium chloride & 140 & 386 & 307 \\
NMDG chloride & 140 & 223 & 321 \\
$\mathrm{NMDG}$ gluconate & 140 & 37 & 33 \\
\hline
\end{tabular}

Endosomes prepared from EE-treated or PE-treated rats were suspended in $140 \mathrm{mmol} / \mathrm{L}$ postassium gluconate buffer. Aliquots $(25 \mu \mathrm{l})$ of endosomes were added to $2 \mathrm{ml}$ buffer of the indicated composition and incubated at $22^{\circ} \mathrm{C}$ for 5 min. Initial rates of acidification were assessed and compared with rates measured in $140 \mathrm{mmol} / \mathrm{L}$ potassium gluconate buffer. Results are the mean of two separate paired preparations of endosomes.

was present; however, replacement of $\mathrm{K}^{+}$with the presumably less permeable cation $\mathrm{NMDG}^{+}$did substantially reduce acidification rates in gluconate medium. These findings suggest that $\mathrm{EE}$ and $\mathrm{PG}$ endosomes exhibit considerable permeability for $\mathrm{Cl}^{-}$and $\mathrm{Br}^{-}$and some permeability for $\mathrm{K}^{+}$. Our findings also suggest that $\mathrm{EE}$ treatment does not generally alter cation or anion permeabilities.

The inhibitory effects of EE were also apparent in potassium-free medium. In three paired preparations, EE-treated and PG-treated endosomes were resuspended in NMDG gluconate buffer $(140 \mathrm{mmol} / \mathrm{L}$ NMDG gluconate and $30 \mathrm{mmol} / \mathrm{L} \mathrm{Bis-Tris}[\mathrm{pH} \mathrm{7.0])}$ and were assayed in NMDG buffers containing various concentrations of gluconate and $\mathrm{Cl}^{-}$. Overall, $\mathrm{PG}$ endosomes in
NMDG medium containing low $\mathrm{Cl}^{-}$acidified at lower rates than did $\mathrm{PG}$ endosomes in $\mathrm{K}^{+}$medium containing equivalent amounts of $\mathrm{Cl}^{-}$, especially in low- $\mathrm{Cl}^{-}$ medium. $\left(0.265\right.$ vs. $0.356 \Delta \mathrm{pH} / \mathrm{min}$ in the absence of $\mathrm{Cl}^{-}$, 0.325 vs. $0.679 \Delta \mathrm{pH} / \mathrm{min}$ in the presence of $2 \mathrm{mmol} / \mathrm{L}$ $\mathrm{Cl}^{-}$and 0.856 vs. $0.943 \Delta \mathrm{pH} / \mathrm{min}$ in $140 \mathrm{mmol} / \mathrm{L} \mathrm{Cl}^{-}$, respectively). In NMDG medium, EE endosomes acidified at rates $10 \%, 2 \%, 8 \%$ and $18 \%$ lower than those of $\mathrm{PG}$ endosomes in the presence of $0,2,25$ and 140 $\mathrm{mmol} / \mathrm{L} \mathrm{Cl}^{-}$, respectively. None of these differences were statistically significantly different. The extent to which EE treatment inhibited acidification in $\mathrm{NMDG}^{+}$ medium was somewhat less than what we observed in $\mathrm{K}^{+}$medium (Fig. 2). This could reflect subtle effects of $\mathrm{EE}$ on $\mathrm{K}^{+}$permeability or a less dominant effect of $\mathrm{EE}$ 


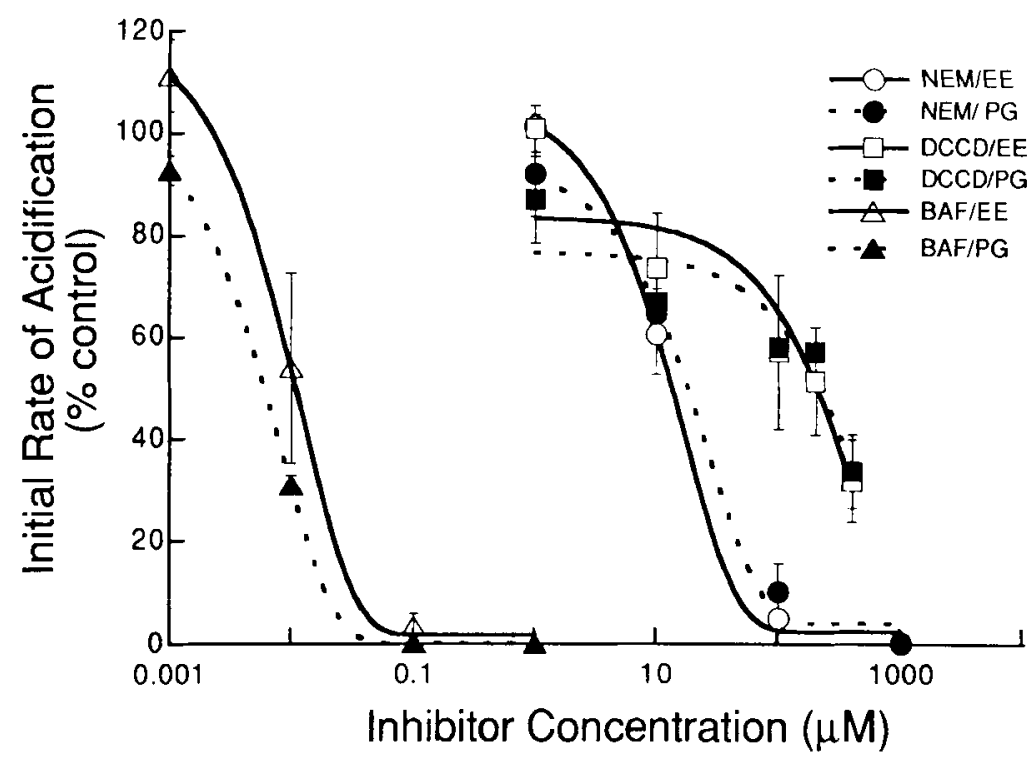

FIG. 4. Effect of proton pump inhibitors on initial rates of acidification of EE-treated and PG-treated endosomes. Endosomes were preincubated for $5 \mathrm{~min}$ in $25 \mathrm{mmol} / \mathrm{L} \mathrm{KCl}, 115 \mathrm{mmol} / \mathrm{L}$ potassium gluconate, $30 \mathrm{mmol} / \mathrm{L}$ Bis-Tris ( $\mathrm{pH} 7.0$ ) buffer with the indicated concentrations of inhibitors before acidification was initiated by addition of $5 \mathrm{mmol} / \mathrm{L} \mathrm{MgATP}$. Results are expressed as percentages of control rates obtained in the same endosome preparation on the same day in assays containing equal volumes of solvent (ethanol for DCCD and NEM, DMSO for bafilomycin $\left.A_{1}\right)$. Curves represent best-fit functions of the form $y=a e^{(-b x)}+c\left(N E M\right.$, Bafilomycin $\left.A_{1}\right)$ or $y=a e^{\prime-b x)}(D C C D)$. We calculated fifty-percent inhibitory dose values from the estimated functions: NEM ( $(\bullet), \mathrm{EE} 13.5 \mu \mathrm{mol} / \mathrm{L}$ and PG $18.1 \mu \mathrm{mol} / \mathrm{L} ; \mathrm{DCCD}(\square, \mathbf{m})$, $\mathrm{EE} 206 \mu \mathrm{mol} / \mathrm{L}$ and PG $216 \mu \mathrm{mol} / \mathrm{L}$; bafilomycin $A_{1}(\triangle, \triangle), E E 11 \mathrm{nmol} / \mathrm{L}$ and PG $6 \mathrm{nmol} / \mathrm{L}$. Symbols represent the mean $\pm \mathrm{S} . \mathrm{E} . \mathrm{M}$. of results from three different paired preparations of endosomes.

on acidification when acidification was severely ratelimited by $\Delta \Psi$.

To investigate further possible structural or kinetic differences in the proton pumps of $E E$ and PG endosomes, we evaluated the inhibitory profiles of three proton pump inhibitors: NEM, which interacts with a critical sulfhydryl group on the catalytic subunit (28); DCCD, which binds covalently in the transmembrane proton channel (29); and bafilomycin $A_{1}$, a macrolide antibiotic isolated from Streptomyces sp. that appears to be a potent and specific inhibitor of vacuolar type $\mathrm{H}^{+}$-ATPases $(30,31)$. As shown in Figure 4, inhibitory profiles and estimated 50\% inhibitory concentrations were similar for EE and PG endosomes with NEM (13.5 and $18.1 \mu \mathrm{mol} / \mathrm{L}$, respectively), DCCD (206 and 216 $\mu \mathrm{mol} / \mathrm{L}$, respectively) and bafilomycin $A_{1}$ (11 and 6 $\mathrm{nmol} / \mathrm{L}$, respectively). Thus $\mathrm{EE}$ treatment did not appear to alter the response to these inhibitors. We showed previously that acidification of EE endosomes is increased by cyclic AMP and protein kinase $A$ to the same degree as control endosomes (33), suggesting that the response to second-messenger systems also is not affected by EE.

Although EE treatment reduced the initial ATPdependent rates of endosome acidification, it had no discernible effect on steady-state intravesicular $\left[\mathrm{H}_{\mathrm{i}}^{+}\right]$, either before or after addition of MgATP (Fig. 5). In the presence of MgATP, steady-state $\left[\mathrm{H}_{i}{ }^{+}\right]$increased as medium chloride increased, reflecting dissipation of $\Delta \Psi$ and an increase in $\Delta \mathrm{pH}(4,27,32)$. However, EE treatment did not alter these values.
Because steady-state $\left[\mathrm{H}_{\mathrm{i}}{ }^{+}\right]$reflects the algebraic sum of proton influx and efflux, we also measured passive proton efflux rates in $\mathrm{KCl}$ and potassium gluconate medium; results are shown in Figure 6. Proton efflux rates reflect the combined effects of proton chemical gradients, membrane potential, intrinsic proton permeability and permeability and gradients of the counterions, principally $\mathrm{K}^{+}$and $\mathrm{Cl}^{-}$. In these studies, proton gradients $\left(\left[\mathrm{H}^{+}{ }_{0}\right]-\left[\mathrm{H}^{+}\right]\right)$were similar for $\mathrm{EE}$ and $\mathrm{PG}$ endosomes $\left(1.2 \times 10^{-6} \mathrm{~mol} / \mathrm{L} \mathrm{H}^{+}[\mathrm{EE}\right.$ and $\mathrm{PG}]$ in $\mathrm{KCl}$ medium and $0.67 \times 10^{-6} \mathrm{~mol} / \mathrm{L} \mathrm{H}^{+}(\mathrm{EE})$ and $0.69 \times 10^{-6} \mathrm{~mol} / \mathrm{L} \mathrm{H}^{+}(\mathrm{PG})$ in potassium gluconate media).

For both EE and PG endosomes, proton efflux rates were faster in potassium gluconate medium than in $\mathrm{KCl}$ medium and this likely primarily reflects the considerable positive ATP-dependent $\Delta \Psi$ that develops in endosomes and other acidified vesicles in potassium gluconate medium $(4,23)$. Indeed, the addition of valinomycin to potassium gluconate medium, which would be expected to reduce the interior positive $\Delta \Psi(25$, $32,34)$ reduced proton efflux rates in both $\mathrm{EE}$ and $\mathrm{PG}$ endosomes.

By contrast, in $\mathrm{KCl}$ medium, the addition of valinomycin increased proton efflux rates in both $\mathrm{EE}$ and $\mathrm{PG}$ endosomes. Because in $\mathrm{Cl}^{-}$medium $\Delta \Psi$ would be expected to be low (4), this observation suggests that in both EE and PG endosomes, proton permeability is greater than $\mathrm{Cl}^{-}$permeability and the latter becomes rate-limiting, resulting in development of an interior negative $\Delta \Psi$ that slows proton efflux. Valinomycin, by 


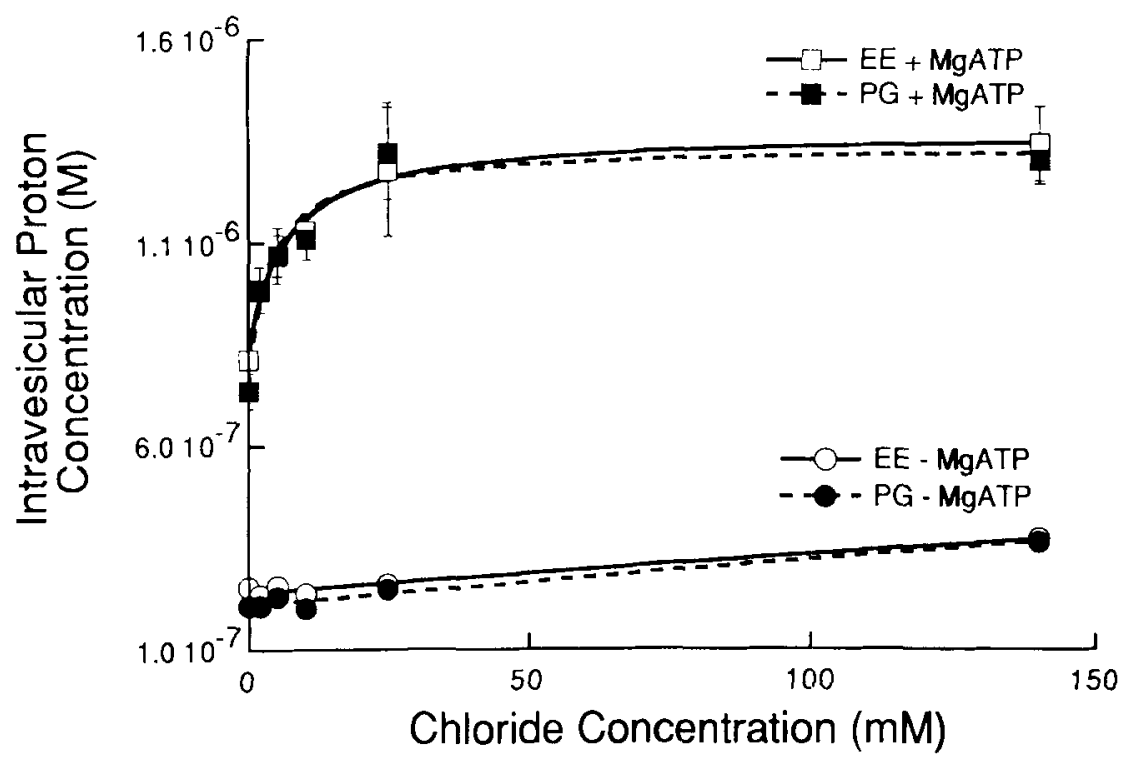

FIG. 5. Steady-state intravesicular proton concentration plotted against medium chloride concentration for EE-treated and PG-treated endosomes measured in the absence $(O, \bullet)$ or presence $(\square,-)$ of MgATP. Symbols represent the mean \pm S.E.M. of values obtained from four to 14 different paired preparations of EE and PG endosomes. S.E.M. bars smaller than the size of symbols are not visible. Curves represent the best-fit functions of the forms $y=a x /(b+x)+c$ (with MgATP) and $y=a x+b$ (without MgATP).

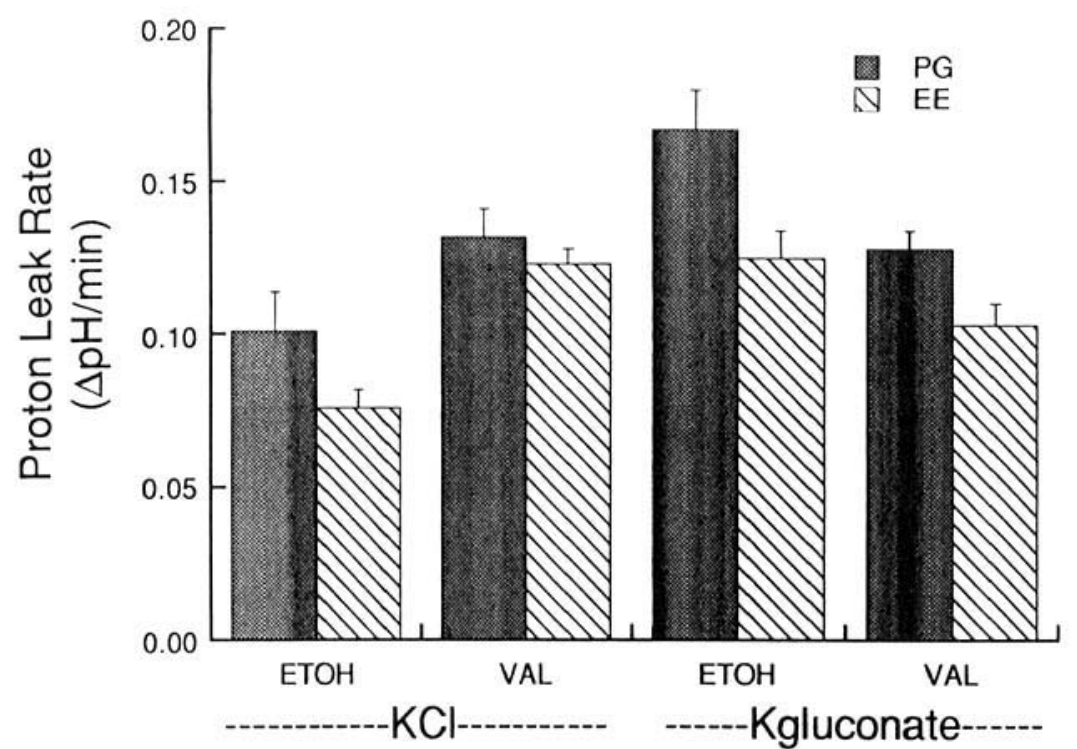

FIG. 6. Effect of EE on endosome proton leak rates. Endosomes treated with EE (hatched bars) and PG (dark bars) were prepared and resuspended in buffer containing $30 \mathrm{mmol} / \mathrm{L}$ Bis-Tris $(\mathrm{pH} 7.0)$ and $140 \mathrm{mmol} / \mathrm{L} \mathrm{KCl}$ or $140 \mathrm{mmol} / \mathrm{L}$ potassium gluconate. Leak rates were measured, as described in Materials and Methods, after addition of small aliquots of ethanol (ETOH) or valinomycin (VAL). Bars represent the mean \pm S.E.M. of values from four or five separate paired preparations of EE-treated and PG-treated endosomes. $\mathrm{Mean} \mathrm{pH}_{\mathrm{i}}$ values when leak rates were measured were 5.87 ( $\mathrm{EE}$ and $\mathrm{PG}$ ) in $\mathrm{KCl}$ medium and 6.09 (PG) and $6.10(\mathrm{EE})$ in potassium gluconate medium. Although we noted a trend toward slower proton leak rates in EE endosomes, none of these differences were statistically significant.

increasing $\mathrm{K}^{+}$permeability $\left(\mathrm{P}_{\mathrm{K}^{+}}\right)$reduces the negative $\Delta \Psi$ and thus increases proton efflux.

Under all the conditions tested, EE endosomes exhibited slower proton efflux rates than PG endosomes, although none of these differences were statistically significant (Fig. 6). These observations suggest that EE treatment modestly reduced endosome proton permeability.
Using values for buffering capacity, we calculated proton efflux rates (millimoles per minute) for EE and $\mathrm{PG}$ endosomes in $\mathrm{KCl}$ medium with valinomycin, conditions likely to minimize any vesicle $\Delta \Psi$, and obtained values of $5.10(\mathrm{EE})$ and $5.65(\mathrm{PG}) \mathrm{mmol} / \mathrm{min}$. These values and the $\left(\left[\mathrm{H}^{+}{ }_{\mathrm{i}}\right]-\left[\mathrm{H}^{+}{ }_{0}\right]\right)\left(1.2 \times 10^{-6} \mathrm{~mol} / \mathrm{L} \mathrm{H}^{+}\right.$ for both $\mathrm{EE}$ and $\mathrm{PG}$ endosomes in $\mathrm{KCl}$ medium) were used to obtain estimates for membrane proton perme- 
ability $\left(\mathrm{P}_{\mathrm{H}}{ }^{+}\right)$of $4.25 \times 10^{3} / \mathrm{min}$ (EE) and $4.71 \times$ $10^{3} / \mathrm{min}$ ( $\mathrm{PG}$ ) with $\mathrm{EE}$ values $11 \%$ lower than $\mathrm{PG}$ values. These values are in the range we measured for $\mathrm{P}_{\mathrm{H}}{ }^{+}$for rat liver endosomes $\left(10.7 \times 10^{3} / \mathrm{min}\right)$, lysosomes $\left(1.27 \times 10^{3} / \mathrm{min}\right)$ and multivesicular bodies $(33.3 \times$ $\left.10^{3} / \mathrm{min}\right)(22,23$; Van Dyke RW, Unpublished observations, 1990-1992). Thus EE treatment may modestly decrease initial rates of acidification and proton efflux rates, resulting in little discernible effect on steadystate, ATP-dependent $\mathrm{pH}_{\mathrm{i}}$.

Finally, the findings illustrated in Figure 6 suggest that valinomycin decreased the differences in proton efflux between $\mathrm{EE}$ and $\mathrm{PG}$ endosomes in $\mathrm{KCl}$ media. This observation might be explained if $\mathrm{EE}$ treatment affected not only proton but also $\mathrm{K}^{+}$permeabilities. If so, then in $\mathrm{KCl}$ medium, $\mathrm{EE}$ endosome proton efflux rates would be limited by both decreased $\mathrm{P}_{\mathrm{H}}{ }^{+}$and $\mathrm{P}_{\mathrm{K}}$, whereas in $\mathrm{KCl}$ medium with valinomycin, proton efflux would be limited (compared with PG endosomes), mainly by decreased $\mathrm{P}_{\mathrm{H}}{ }^{+}$.

\section{DISCUSSION}

EE affects several liver functions. It has been repeatedly shown to cause cholestasis $(14-17,19,35)$; to impair bile acid transport (17-19), Na,K-ATPase (13-17) and $\mathrm{Ca}^{+2}$-ATPase (20); and to alter cytochrome P-450 (36). EE also appears to alter endocytic and vesicular traffic of a variety of proteins. It increases release of lysosomal enzymes and lysosomal contents into bile (37), decreases the transcytotic movement of IgA from blood to bile (12) and increases the proportion of ASOR subjected to endocytosis that escapes lysosomal degradation and is released intact in bile (12). The mechanisms by which $E E$ exerts all of these effects are not well understood; however, possible mechanisms include changes in (a) membrane cholesterol ester and phospholipid composition $(13,15,16)$; (b) membrane fluidity (13-16); (c) synthesis, function or both of proteins (17-19, 36); and (d) formation, sorting, targeting and fusion of endocytic and exocytic intracellular vesicles $(12,37)$.

Endocytic vesicles are acidified by an electrogenic proton pump or vacuolar $\mathrm{H}^{+}$-ATPase that functions in conjunction with a halide conductance to maximally acidify the interior of vesicles while minimizing $\Delta \Psi(2-5$, 32 ). Endocytic vesicles progressively acidify after formation, with lysosomes exhibiting the most acidic $\mathrm{pH}_{\mathrm{i}}$ (8-10). Although the proton pump responsible for vesicle acidification has been identified in many intracellular organelles, little is known about potential regulatory mechanisms for this pump. Because EE has been shown to alter a number of steps in receptor-mediated endocytosis, we embarked on this study to determine whether this hormone alters endosome acidification. For these studies, we employed a conventional treatment protocol that reproducibly produces cholestasis in rats (13-16); each estrogen-treated rat was treated in parallel with a littermate control animal. Endosomes were prepared simultaneously from each of the paired animals (EE and PG) on each experimental day, and vesicles were studied under identical conditions. For this study, we chose to examine acidification in all endocytic vesicles formed over a 10-min period to include very early and sorting endosomes, such as compartment for uncoupling of receptors and ligands vesicles (CURL vesicles) in our experiments. Also, we employed a technique for assessing endosome acidification that is independent of the number of vesicles studied and vesicle FITC-dextran content. Thus our results would not be affected by differences in the number or size of endocytic vesicles formed during exposure to FITC-dextran (21-24).

Whether the endosomes prepared from EE-treated rats are the same vesicles prepared from PG-treated rats cannot be definitively answered from our studies; techniques to unambiguously define and isolate subsets of early endocytic vesicles are not well developed. In addition, endosome populations may be defined by one or more of several sets of criteria, including morphological shape, content of receptors and ligands, time elapsed since formation, composition of membrane proteins, derivation from coated-pit or non-coated-pit areas and presence of various proteins that determine endosome trafficking. After formation, endosomes rapidly remodel and sort contents into a variety of vesicles destined for many different pathways. Thus criteria are likely to define overlapping rather than distinct populations of vesicles. We therefore chose to study vesicles loaded with the fluid-phase marker FITCdextran to study the effects of EE on ion transport of all endocytic vesicles formed by hepatocytes in a defined time period.

The principal finding of this study was that treatment with EE resulted in small but consistent and statistically significant decreases in the initial rates of acidification in FITC-dextran-loaded endocytic vesicles. The mechanism of this change was not established from our studies; however, ion-substitution studies (Table 2, Fig. 2), inhibitor profiles (Fig. 4) and MgATP kinetics (Fig. 3) suggest that EE did not alter the subunit structure of the proton pump, its affinity for ATP, rate limitations imposed by chloride availability or general responses to ion substitution. Our findings indicate that the $\mathrm{V}_{\max }$ of acidification was decreased (Fig. 2), an observation usually attributed to a decrease in the number or turnover rate of pump units.

These differences in acidification between EE-treated and PG-treated endosomes may represent changes in one or more of the following factors: (a) number of proton pumps inserted per unit of endosome membrane surface area during vesicle formation or during endosome remodeling, (b) vesicle surface-to-volume ratio (22), (c) proton pump turnover rate, (d) vesicle buffering capacity, (e) counterion permeability, (f) presence of other electrogenic ion pumps (38) and (g) regulatory factors such as phosphorylation by protein kinase A (33). EE treatment could affect any one or more of these factors, some of which could be considered as defining a different "subset" of endosomes. For example, EE might alter synthesis or correct insertion of proton pumps into endocytic vesicles, as has been proposed to 
explain the effects of estrogen on cytochrome P-450 (36) and the canalicular ATP-dependent bile acid transporter (19). Alternatively, because we have shown that early endosomes (prepared after 2-min or 10-min exposure to FITC-dextran) acidify faster than more "mature," later endosomes (CURL vesicles and multivesicular bodies), which in turn acidify faster than lysosomes (22; Van Dyke RW, Unpublished observations, 1990-1992), it is possible that EE modestly changes the rates of formation or remodeling and maturation of endosomes such that vesicles formed over $10 \mathrm{~min}$ by EE-treated livers included more "mature" vesicles with decreased rates of acidification.

$\mathrm{EE}$ also might alter the turnover rate of individual proton pumps, possibly through changes in endosome lipid composition. The vacuolar $\mathrm{H}^{+}$-ATPase activity isolated from brain clathrin-coated vesicles has been shown to be sensitive to changes in membrane phospholipid and cholesterol composition (39), and EE is known to increase cholesterol esters, sphingomyelin and several phospholipids in hepatic plasma membranes $(15,16)$. It is not known, however, whether estrogen alters the lipid composition of endocytic vesicles (lipid composition of our endosomes could not be assessed because the preparation was not pure) or whether changes in lipid composition alter proton transport, as opposed to ATP hydrolysis, of the vacuolar proton pump.

Our results also suggest that EE treatment alters endosome $\mathrm{K}^{+}$permeability, as indicated by the smaller effects of $\mathrm{EE}$ on acidification in $\mathrm{NMDG}^{+}$medium compared with that in $\mathrm{K}^{+}$medium and by the lesser effects of $\mathrm{EE}$ on proton leak rates in $\mathrm{KCl}$ medium with valinomycin. Further studies that directly assess $\mathrm{K}^{+}$ permeability and determine its role in regulating endosome acidification will be needed to confirm this possibility.

Finally, our own studies suggest that the last two factors are unlikely explanations for the effects of EE. We have shown similar effects of cAMP and protein kinase $\mathrm{A}$ on $\mathrm{EE}$ and control endosomes (33), and we have failed to identify functionally significant $\mathrm{Na}, \mathrm{K}$-ATPase in rat liver early endosomes (38).

Clearly, additional studies using highly purified and well-characterized populations of endosomes or of purified proton pumps will be required to differentiate effects of estrogens on pump turnover rate from effects on membrane proteins and on lipid composition or on the "maturity" or geometric configuration of endosomes.

EE not only affected initial rates of endosome acidification; it also reduced vesicle proton leak rates, measured either as $\Delta \mathrm{pH} / \mathrm{min}$ (Fig. 6) or as a flux (in $\mathrm{mmol} / \mathrm{min}$ ). Indeed, these two changes appeared to counterbalance each other to the extent that estrogen did not alter steady-state ATP-dependent $\mathrm{pH}_{\mathrm{i}}$ (Fig. 5). To examine this issue further, we calculated apparent proton permeability coefficients from flux rates and the transmembrane proton gradient (25) under conditions ( $\mathrm{KCl}$ medium with valinomycin) that would be expected to minimize $\Delta \Psi$. Biological membranes exhibit a rela- tively high passive permeability for protons compared with other ions (40), and the values we measured in this study were similar to values measured in a variety of epithelial plasma membranes $(25,34,41,42)$. EE treatment decreased $\mathrm{P}_{\mathrm{H}}+$ by about $11 \%$. The mechanism for these changes in $\mathrm{P}_{\mathrm{H}^{+}}$is not known, but because increases in plasma membrane fluidity have been correlated to increases in $\mathrm{P}_{\mathrm{H}}+$ in renal and gastroduodenal apical plasma membranes $(41,42)$, it is possible that estrogen-induced decreases in endosome $\mathrm{P}_{\mathrm{H}^{+}}$are also related to decreased membrane fluidity. These changes in $\mathrm{P}_{\mathrm{H}^{+}}$are not likely due to the effects of increased bile salts in cholestatic liver; bile salts increase rather than decrease $\mathrm{P}_{\mathrm{H}^{+}}$in duodenal membrane vesicles (43).

Overall, our findings indicate that after treatment with $\mathrm{EE}$, rat liver endosomes formed over a 10-min period exhibit modestly decreased rates of acidification. These changes are small, but they might affect the efficiency of uncoupling of receptor from ligand during the early stages of receptor-mediated endocytosis because this step is dependent on modest changes in endosome $\mathrm{pH}_{\mathrm{i}}$. Because steady-state endosome $\mathrm{pH}_{\mathrm{i}}$ was not affected by estrogen treatment, it is unlikely that estrogen affects acidification and function of late endocytic vesicles, such as lysosomes, that have presumably achieved steady-state $\mathrm{pH}_{\mathrm{i}}$. Our findings and those of others may provide a partial explanation for some of the EE-induced abnormalities in endocytosis noted by Goldsmith et al. (12). For example, chloroquine is known to impair endosome acidification and to partially alkalinize endocytic vesicles and lysosomes in intact cells $(44,45)$. Chloroquine, like estrogen, also delays biliary excretion of IgA and transfer of ligands subjected to endocytosis to lysosomes (46), suggesting that some of these abnormalities in handling ligands subjected to endocytosis may in part be related to small changes in vesicle acidification. Further studies correlating changes in vesicle $\mathrm{pH}_{\mathrm{i}}$ with handling of macromolecules subjected to endocytosis in intact cells will be needed to confirm this hypothesis. Finally, it is possible that estrogens also affect other aspects of endocytosis such as vesicle formation, receptor sorting and membrane fusion.

Acknowledgments: We thank Dr. Maan Anbari for assistance with some of the assays and Ms. Cheryl Swanigan for manuscript preparation.

\section{REFERENCES}

1. Anderson RGW, Orci L. A view of acidic intracellular compartments. J Cell Biol 1988;106:539-543.

2. Van Dyke RW. Acid transport by intracellular vesicles. J Int Med 1990;228(suppl 1):41-46.

3. Forgac M. Structure and function of vacuolar class of ATP-driven proton pumps. Physiol Rev 1989;69:765-796.

4. Van Dyke RW. Proton pump-generated electrochemical gradients in rat liver multivesicular bodies. J Biol Chem 1988;263:26032611.

5. Xie S-X, Crider BP, Stone DK. Isolation and reconstitution of the chloride transporter of clathrin-coated vesicles. J Biol Chem 1989;264:18870-18873.

6. Mulberg AE, Tulk BM, Forgac M. Modulation of coated vesicle 
chloride channel activity and acidification by reversible protein kinase A-dependent phosphorylation. J Biol Chem 1991;266: 20590-20593.

7. Barasch J, Gershon MD, Nunez EA, Tamir H, Al-Awqati Q. Thyrotropin induces the acidification of the secretory granules of parafollicular cells by increasing the chloride conductance of the granular membrane. J Cell Biol 1988;107:2137-2147.

8. Gruenberg J, Howell KE. Membrane traffic in endocytosis: insights from cell-free assays. Annu Rev Cell Biol 1989;5:453-481.

9. Mellman I, Fuchs R, Helenius A. Acidification of the endocytic and exocytic pathways. Annu Rev Biochem 1986;55:663-700.

10. Kornfeld S, Mellman I. The biogenesis of lysosomes. Annu Rev Cell Biol 1989;5:483-525.

11. Steer CJ, Ashwell G. Receptor-mediated endocytosis: mechanisms, biologic function, and molecular properties. In: Zakim D, Boyer TD, eds. Hepatology: a textbook of liver disease. 2nd ed. Philadelphia: W.B. Saunders, 1990:137-182

12. Goldsmith MA, Jones AL, Underdown BJ, Schiff JM. Alterations in protein transport events in rat liver after estrogen treatment. Am J Physiol 1987;253:G195-G200.

13. Davis RA, Kern F Jr, Showalter R, Sutherland E, Sinensky M, Simon FR. Alterations of hepatic $\mathrm{Na}^{+}, \mathrm{K}^{+}$-ATPase and bile flow by estrogen: effects on liver surface membrane lipid structure and function. Proc Natl Acad Sci USA 1978;75:4130-4134

14. Simon FR, Gonzalez M, Sutherland E, Accatino L, Davis RA Reversal of ethinyl estradiol-induced bile secretory failure with Triton WR-1339. J Clin Invest 1980;65:851-860.

15. Rosario J, Sutherland E, Zaccaro L, Simon FR. Ethinylestradiol administration selectively alters liver sinusoidal membrane lipid fluidity and protein composition. Biochemistry 1988;27:39393946.

16. Smith $\mathrm{DH}$, Gordon ER. Role of liver plasma membrane fluidity in the pathogenesis of estrogen-induced cholestasis. J Lab Clin Med 1988;112:679-685.

17. Berr F, Simon FR, Reichen J. Ethynyl estradiol impairs bile salt uptake and Na-K pump function of rat hepatocytes. Am $\mathrm{J}$ Physiol 1984;247:G437-G443.

18. Stacey NH. Effects of ethinyl estradiol on substrate uptake and efflux by isolated rat hepatocytes. Biochem Pharm 1986;35:24952500.

19. Meier PJ, Bossard R, O'Neil B, Stieger B. Ethinylestradiol induced cholestasis is associated with decreased ATP-dependent bile acid transport in canalicular membranes of rat liver [Abstract]. HEPATOLOGY 1992;16:567.

20. Moore L, Knapp HR Jr, Landon EJ. An effect of estradiol and testosterone on the calcium pump activity and phospholipid fatty acid composition of rat liver microsomes. Endocrinology 1977; 100:1516-1520.

21. Ohkuma S, Poole B. Fluorescence probe measurement of the intralysosomal $\mathrm{pH}$ in living cells and the perturbation of the $\mathrm{pH}$ by various agents. Proc Natl Acad Sci USA 1978;75:3327-3331.

22. Van Dyke RW, Matsumoto-Pon JK. Acidification of rat liver endosomes: similarities and differences [Abstract]. HEPATOLOGY 1989;10:597.

23. Van Dyke RW. Acidification of rat liver lysosomes: quantitation and comparison to endosomes. Am J Physiol, in press.

24. Tsein RY, Poenie M. Fluorescence ratio imaging: a new window into intracellular ionic signaling. Trends Biochem Sci 1986;11: 450-455.

25. Lencer WI, Verkman AS, Arnaout MA, Ausiello DA, Brown D. Endocytic vesicles from renal papilla which retrieve the vasopressin-sensitive water channel do not contain a functional $\mathrm{H}^{+}$ATPase. J Cell Biol 1990;111:379-389.
26. Lowry OH, Rosebrough NJ, Farr AL, Randall RJ. Protein measurement with the Folin phenol reagent. J Biol Chem 1951;193:265-275.

27. Van Dyke RW. Anion inhibition of the proton pump in rat liver multivesicular bodies. $J$ Biol Chem 1986;261:15941-15948.

28. Moriyama $Y$, Nelson N. Nucleotide binding sites and chemical modification of the chromaffin granule proton ATPase. J Biol Chem 1987;262:14723-14729.

29. Arai $H$, Berne M, Forgac M. Inhibition of the coated vesicle proton pump and labeling of a 17,000-dalton polypeptide by $\mathrm{N}, \mathrm{N}^{\prime}$ dicyclohexylcarbodiimide. J Biol Chem 1987;262:11006-11011.

30. Bowman EJ, Siebers A, Altendorf K. Bafilomycins: a class of inhibitors of membrane ATPases from microorganisms, animal cells, and plant cells. Proc Natl Acad Sci USA 1988;85:79727979 .

31. Yoshimori T, Yamamoto A, Moriyama Y, Futai M, Tashiro Y. Bafilomycin $A_{1}$, a specific inhibitor of vacuolar-type $H+-A^{\prime} T$ Pase, inhibits acidification and protein degradation in lysosomes of cultured cells. J Biol Chem 1991;266:17707-17712.

32. Moriyama $Y$, Nelson $N$. Internal anion binding site and membrane potential dominate the regulation of proton pumping by the chromaffin granule ATPase. Biochem Biophys Res Commun 1987;149:140-144.

33. Hsi RA, Ash KV, Ervin LL, Van Dyke RW. Effect of cAMP on acidification of rat liver endosomes. Gastroenterology 1991;100: A828.

34. Ives HE. Proton/hydroxyl permeability of proximal tubule brush border vesicles. Am J Physiol 1985;248:F78-F86.

35. Kreek MJ. Female sex steroids and cholestasis. Semin Liver Dis 1987;7:8-23

36. MacKinnon M, Sutherland E, Simon FR. Effects of ethinyl estradiol on hepatic microsomal proteins and the turnover of cytochrome P-450. J Lab Clin Med 1977;90:1096-1106.

37. Lopez del Pino VH, LaRusso NF. Dissociation of bile flow and biliary lipid secretion from biliary lysosomal enzyme output in experimental cholestasis. J Lipid Res 1981;22:229-235.

38. Anbari M, Root KV, Ervin LL, Van Dyke RW. Na,K-ATPase plays no role in regulating acidification of early rat liver endocytic vesicles [Abstract]. Gastroenterology 1993;104:A870.

39. Xie X-S, Tsai S-J, Stone DK. Lipid requirements for reconstitution of the proton-translocating complex of clathrin-coated vesicles. Proc Natl Acad Sci USA 1986;83:8913-8917.

40. Deamer DW, Nichols JW. Proton flux mechanisms in model and biological membranes. J Membr Biol 1989;107:91-103.

41. Ives HE, Verkman AS. Effects of membrane fluidizing agents on renal brush border proton permeability. Am J Physiol 1985;249: F933-F940.

42. Wilkes JM, Ballard HJ, Dryden DTF, Hirst BH. Proton permeability and lipid dynamics of gastric and duodenal apical membrane vesicles. Am J Physiol 1989;256:G553-G562.

43. Zhao D, Hirst BH. Bile salt-induced increases in duodenal brush-border membrane proton permeability, fluidity, and fragility. Dig Dis Sci 1990;35:589-595.

44. Maxfield FR. Weak bases and ionophores rapidly and reversibly raise the $\mathrm{pH}$ of endocytic vesicles in cultured mouse fibroblasts. J Cell Biol 1982;95:676-681.

45. Van Dyke RW, Faber ED, Meijer DKF. Sequestration of organic cations by acidified hepatic endocytic vesicles and implications for biliary excretion. J Pharmacol Exp Ther 1992;261:1-11.

46. Limet JH, Quintart J, Schneider Y-J, Courtoy PJ. Receptormediated endocytosis of polymeric IgA and galactosylated serum albumin in rat liver. Eur $\mathrm{J}$ Biochem 1985;146:539-548. 